\title{
THE RELATION OF TREATMENT AND ECOLOGICAL EFFECTS IN BRACKISH WATER REGIONS
}

\author{
RUTGER ROSENBERG \\ Swedish Waterand Air Pollution Research Laboratory,P.O. Box 5207, S-40224Gothenburg, Sweden
}

\begin{abstract}
The ecosystems in brackish water regions are already exposed to stress, especially those living in estuaries with their fluctuating environment. The question raised here is whether these ecosystems are generally more susceptible to additional stress such as pollution, or if their ability to adapt to environmental changes leads to increased tolerance to pollution.

The Baltic, as being the largest brackish water area in the world, is discussed with respect to its eutrophication in relation to pollution discharge. A comparative analysis of the effects of pulp and paper mill effluents in the brackish water environment is made between a polluted area in the Bothnian Sea and an estuarine area under recovery on the Swedish west coast.

The question of stress tolerance of ecosystems is extremely important when it comes to predicting environmental and ecological effects. It is suggested here that, in general, already stressed ecosystems are more tolerant to pollution than those existing in stable environments, and thus, the brackish water environment is less susceptible than similar marine environments.
\end{abstract}

Discharge of polluted water brings about disorders in aquatic ecosystems. Severe pollution disrupts ecosystems and reduces them to poor levels of organisation.

Waste water is often transported to sea by river water. Estuaries are transition zones outside river mouths, where fresh water and marine water meet. However, the water here is simply diluted sea water, which is the same as brackish water. According to the Venice Classification System, brackish water has a salinity of between 0.5 and 30 ppt.

Brackish water regions cause stress to the ecosystem because of their fluctuating environmental conditions. This stress reduces the species diversity. If we increase this stress by adding polluting wastes to the brackish water regions-which is commonly done today-this leads, according to most authorities on pollution problems, to more severe consequences for the ecosystem than if we pollute similar marine regions.

This is a question of stress tolerance of ecosystems which is extremely important when it comes to predicting the environmental and ecological effects.

The largest brackish water sea in the world is the Baltic Sea, covering $366,000 \mathrm{~km}^{2}$. It is also one of the worlds largest polluted areas. The surface salinity is $8 \mathrm{ppt}$ in the southern parts, decreasing gradually northwards to 2-3 ppt in the Bothnian Bay. The flow of nutritious waste water from communities and industrial plants has tended to increase the biological production, particularly in coastal waters. The major part of organic waste emitted to the Baltic from Sweden originates from the forest industry. ${ }^{1}$ However, during the last couple of years, a significant decrease in the discharge of organic waste from the pulp and paper industry has occurred. ${ }^{2}$ If these coastal discharges are added to the wastes transported by rivers, we arrive at a total Swedish contribution to the annual load on the Baltic in the order of 60,000 tons of nitrogen, 7000 tons of phosphorus and $1,500,000$ tons of organic matter.

The oxygen situation in the deep basins of the Baltic proper has deteriorated during the twentieth century due to, among other things, a rise in the salinity and temperature of the bottom water. $^{3}$ However, the occurrence of hydrogen sulphide has not yet the permanent character of that in, e.g. the Black Sea; in the
Baltic it varies with the exchange of water with the North Sea. The alternatic oxic and anoxic conditions in the bottom water is proposed to be the driving force behind an increasing eutrophicatin of the Baltic. During stagnation periods, decaying organic matter is accumulated in the deep water. When the conditions of the stagnant deep waters change from oxidising to reducing as a result of this decay, nutrients-especially phosphorus-are dissolved from the sediments. Through upwelling, these released nutrients may then be transported up to the surface, where photosynthesis can take place. This process is also reflected in the increasing concentrations of dissolved phosphorus in the surface water of the Central Baltic Basin observed from 1950 to $1968 .{ }^{3}$

Periods of stagnation under anoxic conditions in the deep basins is most probably a natural phenomenon, and it has recently been shown to be correlated with paleo-climatic variations. The increased pollution during the last decades has perhaps accelerated this process. Local damages in the Baltic ecosystem may be reversible, but a general disturbance of the total ecosystem in such a closed sea area as the Baltic may be irreversible and must therefore be prevented.

I will now give two examples of the effects of industrial waste water on brackish water ecosystems. One example is from the Bothnian Sea in the Baltic, the other from an estuary on the Swedish west coast. The waste water in both cases was discharged from pulp and paper industries, and the effects were studied by examining the benthic fauna. This fauna contains, for instance, clams, polychaetes and crustaceans living in tubes or burrows in the top layer of the sediments or on the surface of the sediments. They can be very abundant, in numbers of several thousands per $\mathrm{m}^{2}$. The benthic animals form communities with restricted organisation. They live in the same spot for years and, thus, changes in the community structure are indications of environmental changes in that particular area. Analysis of the benthos can therefore be used to assess the degree of pollution in an area.

The first example is from the Bothnian Sea (Fig. 1), (see Rosenberg et al. $^{4}$ ).

In 1972, the organic wastes from the kraft pulp mill at Köpmanholmen was equivalent to about 8000 tons $\mathrm{BOD}_{7} \mathrm{yr}^{-1}$ which was roughly $2 \%$ of the total contribution 


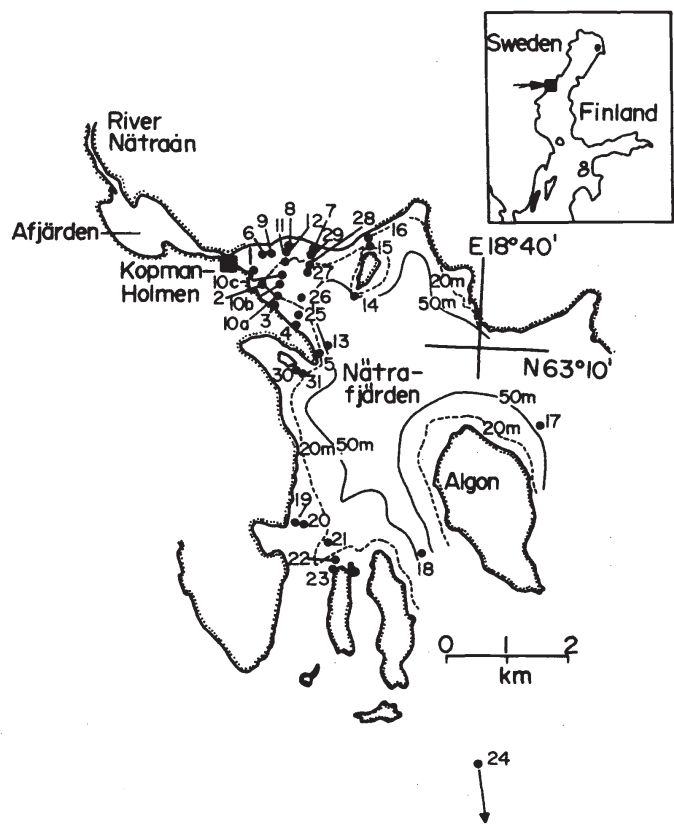

Fig. 1. Köpmanholmen and benthic sampling stations (after Rosenberg et al. 1974).

to the Bothnian Sea. BOD and $\mathrm{KMnO}_{4}$-consumption of about $150 \mathrm{mg}^{-1}$ were found in the surface water in the spring of 1971. In the bottom water these values were $1 / 10$ lower.

During the period 1969-1972, no benthic fauna was found at the inner 12 sampling stations, representing an area of approx. $1 \mathrm{~km}^{2}$. Had no waste water been discharged, there would have been an estimated 60 tons of benthic organisms living in this area.

Figure 2 shows the result of a statistical analysis of the benthic communities. One can see three distinctly separate groups of stations, the three black triangles. On the basis of the benthic community analysis one is able to

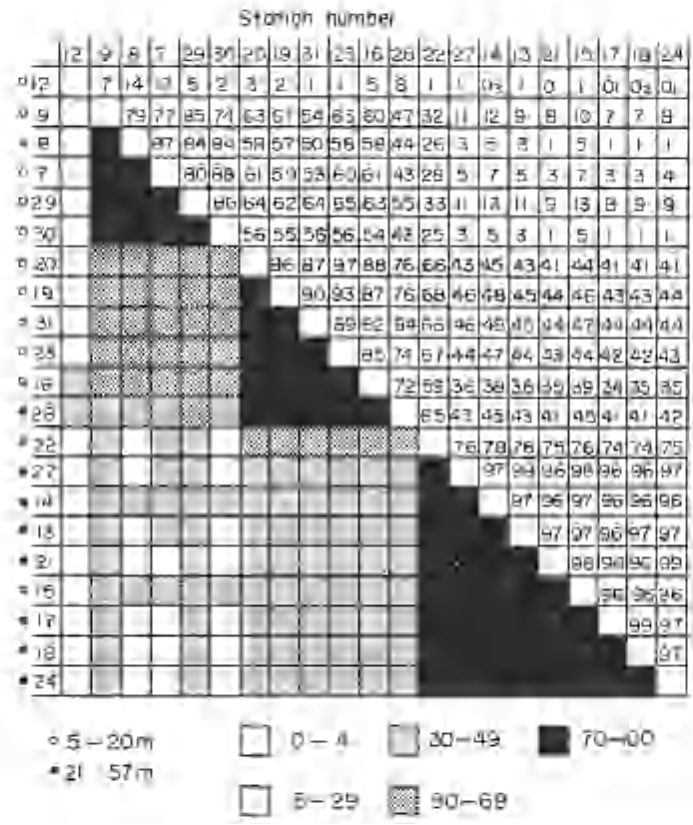

Fig. 2. Percentage faunal similarity between pairs of stations in Nätrafjärden 1972 (after Rosenberg et al. 1974). estimate the distribution and degree of pollution in an area (Fig. 3).

The second example of a brackish water region exposed to industrial waste water is Saltkällefjorden on the Swedish west coast (Fig. 4) (see Rosenberg. ${ }^{\text {.-8) }}$ ) This estuary received waste water from the sulphite pulp mill at Munkedal for about 100 yr. The pulp mill closed down in 1966, and the discharged volume of waste water was thereby reduced from $55,000 \mathrm{~m}^{3}$ per day to $1 / 10$ of that volume and the amount of filtered dry substance from 25 tons to $0 \cdot 1$ ton per day. During the time of operation of the mill, the benthic faunal biomass in the inner parts of Saltkällefjorden decreased in an area of $1.5 \mathrm{~km}^{2}$ by approx 60 tons, i.e. the same quantity mentioned above

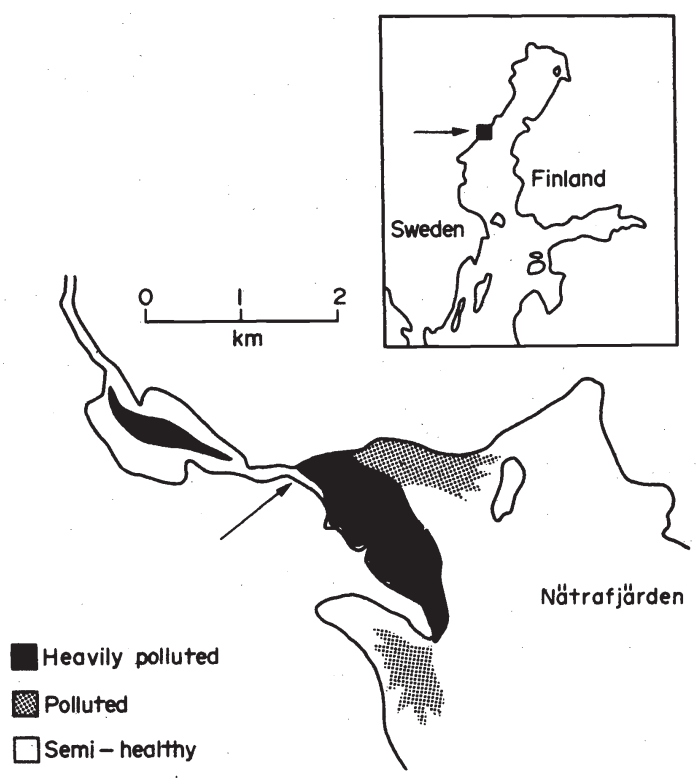

Fig. 3. Different pollution zones outside Köpmanholmen. Arrow indicates effluent discharge.

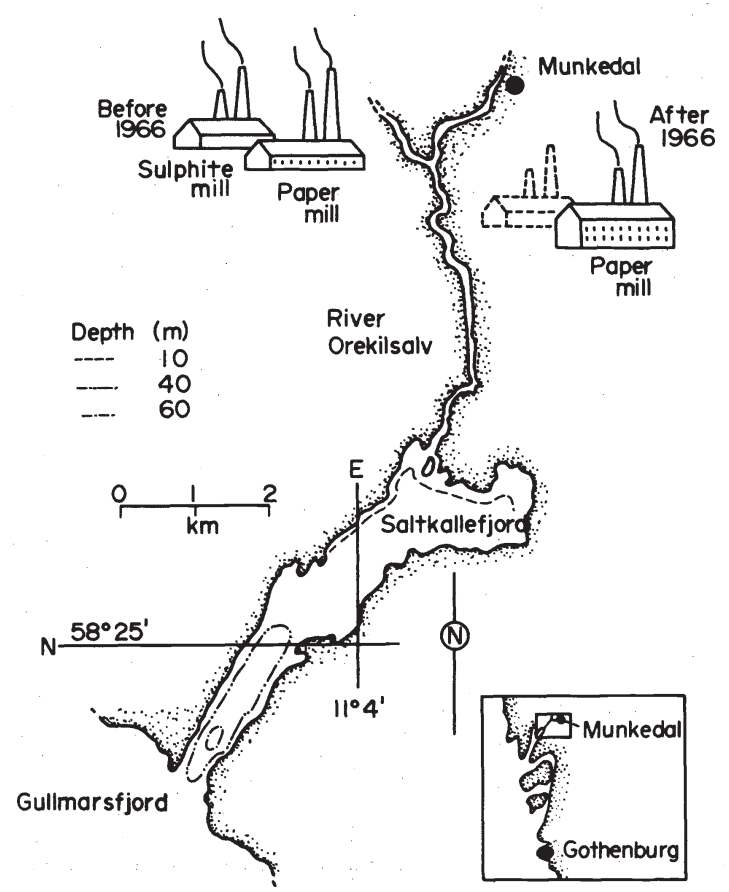

Fig. 4. Saltkällefjorden on the Swedish west coast with the sulphite pulp mill at Mundetdel. 
for Köpmanholmen in the Bothnian Sea. What happened then after the pollution abatement in 1966 in Saltkällefjorden?

The fauna colonized the bottoms successively and after about $5 \mathrm{yr}$ (i.e. in 1971) the 60 tons of living organisms were back. Figure 5 shows the increase in number of benthic species at some localities in the inner part of Saltkällefjorden during 1968 to 1970 . Observe the heavy increase month by month in 1969 , and the increase from 0 species in 1968 to 25 species in 1970 at station L6, L28.

Four different periods in the history of Saltkällefjorden are summarised in Fig. 6: The "healthy-species" curve from 1932 when the estuary was almost unpolluted; the curve for the polluted period prior to the closure of the pulp mill, and two curves illustrating the successive recovery of the estuary, the last one (1971) indicating the formation of highly organized benthic communities.

Figure 7 shows the beautiful colonization of some commonly known littoral species.

\section{ECOSYSTEM STRESS TOLERANCE}

The following is a discussion in more general terms of the stress tolerance of ecosystems, with some brief comparisons between brackish water and marine water systems.

Ecologists all over the world have for years been requesting studies and evaluations to predict the environmental and ecological effects of man's operations prior to their execution.

Most of our predictions are made from analogies. For instance, we have observed that a certain quantity of waste water from paper and pulp industries has a certain effect in one area. By looking at a dilution gradient we can get an idea, even from this single case, of the concentration-effect relationship. For the new situation that we are to predict we apply our observations from the studied area and make calculations on expected pollution gradients.

Obviously, a variety of questions remain unanswered. One of them concerns the differences in sensitivity between different ecosystems. Can we assume that all ecosystems are equally sensitive to stress? Evidently not. Then: which are the more and which are the less sensitive ones?

This question is one of many of fundamental importance when a prediction of ecosystem response is made with the technique of analogy. It is also a question of large principle importance in fundamental ecology. It is raised here because scientists disagree on the answer, and
- $1932 \quad 01969$

०1965 $\Delta 1971$

$\bullet 1968$

Depth L19 L17 LI5 LI2 L9 L5

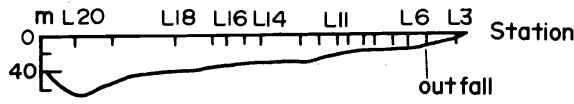

Number of species

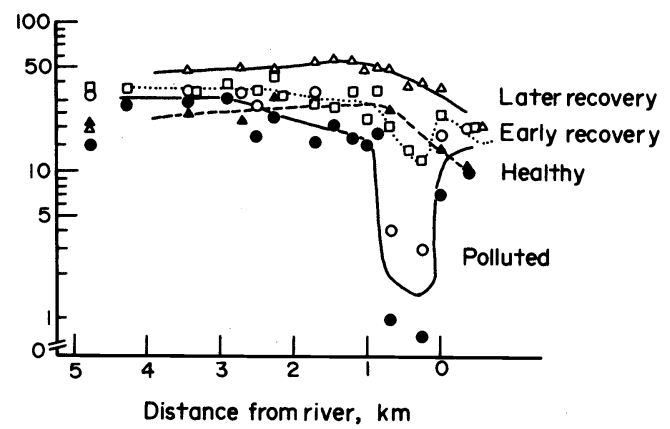

Fig. 6. Number of species during four periods in Saltkällefjorden (after Rosenberg 1973).

because this disagreement discloses a basic lack of ecological understanding that is vitally important to overcome.

An ecosystem with a high degree of constancy in physical parameters and a large number of species is referred to as one with high stability. Consequently, an ecosystem with varying (and unpredictable) physical parameters and few species is characterized by a large variation in the number of individuals within the species and referred to as one with low stability.

Following this concept of stability, together with the assertion that species living under extreme conditions are already subject to severe stress and consequently more vulnerable to additional stress factors, it is frequently argued that e.g. the Baltic must be regarded as more susceptible than e.g. the North Sea and thus in need of stricter rules for protection. This argument then is partly based on the idea that a system with high stability is less sensitive to additional stress than an unstable system. Examining the logic and content of the word stability and using examples from different ecosystems, I want to present the conclusions I have drawn from my experience with regard to stress tolerance of ecosystems.

The word stability as refered to above basically means

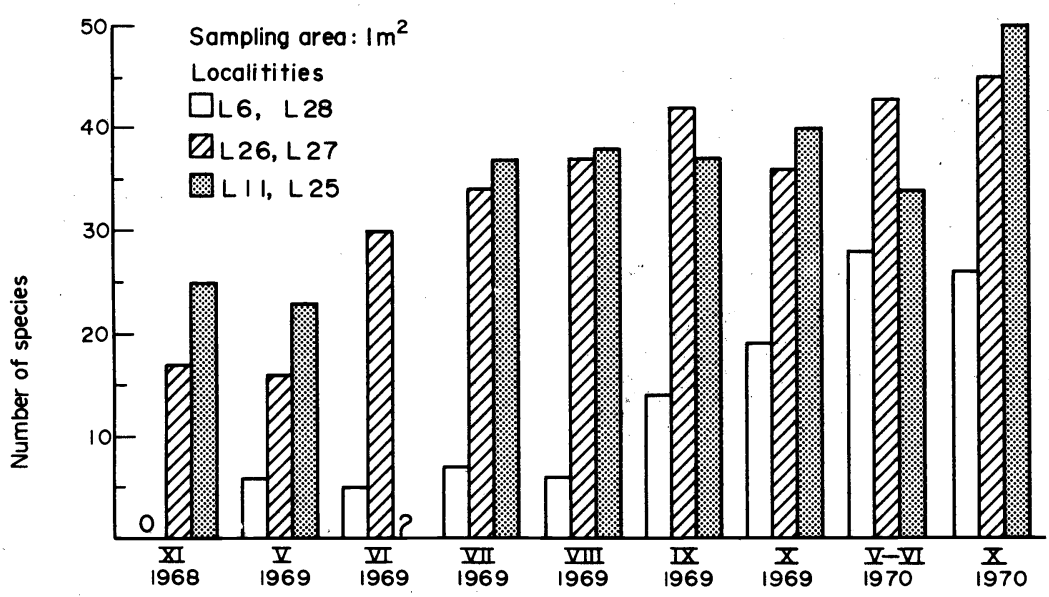

Fig. 5. Recolonisation of species at some localities in the inner part of Saltkällefjorden (after Rosenberg 1972). 

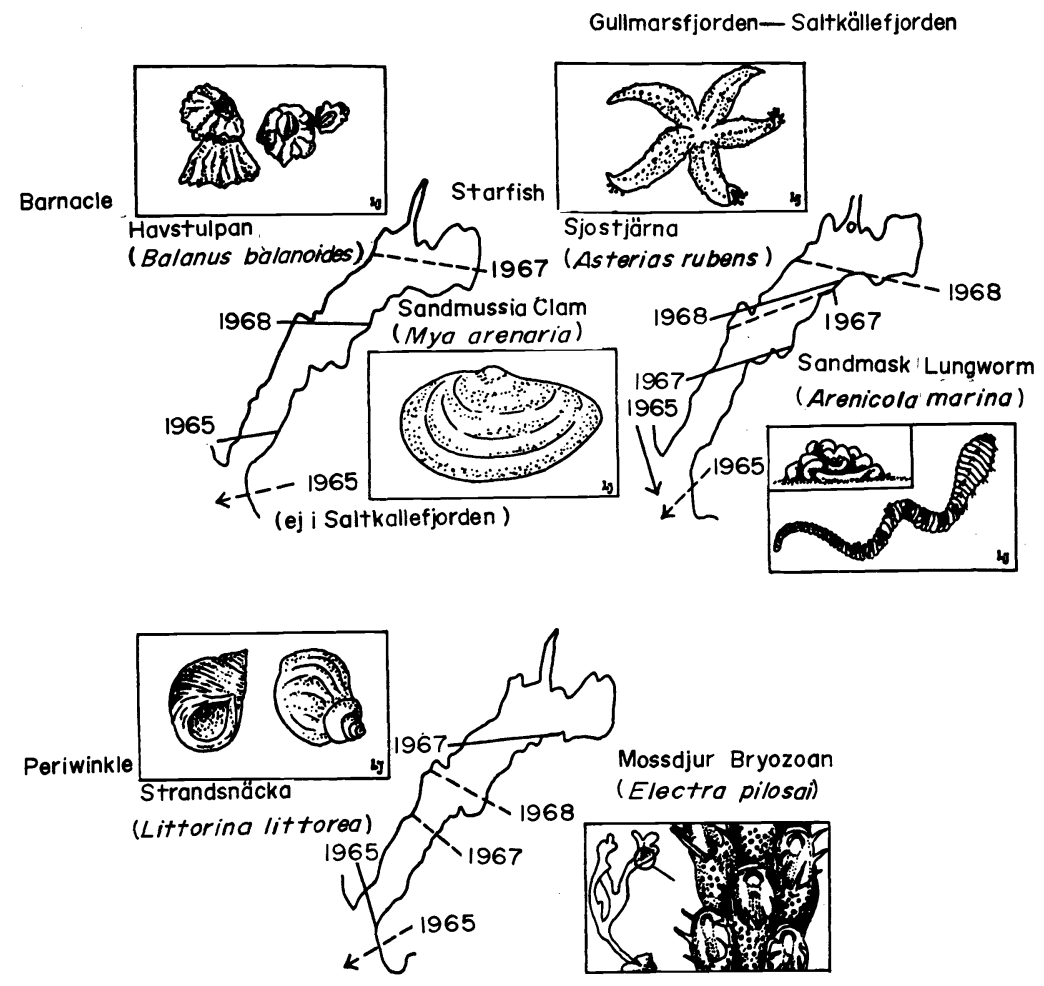

Fig. 7. Inner distribution limits of some littoral species in Saltkällefjorden before and after the closure of the sulphite pulp mill in 1966.

"small variation in the number of individuals within a species", or "ability to reduce fluctuation in number of species through a feed-back system of predation/competition pressure".

Variations in an environment, e.g. through seasonal climate, are also reflected by fluctuations in the ecosystem. This means that low diversity ecosystems are associated with unstable environmental factors. In an estuary, the salinity increases with increased distance from the river mouth and thus also the diversity. The Baltic can be regarded as a large estuary. The ecosystem in the Baltic has a low diversity precisely because of the reduced salinity. Since the organisms are already exposed to stress, they would then, according to conventional theories, be less resistant to an additional stress factor (such as pollution).

What happens then in an estuary when it is exposed to pollution? In the study on the effects of sulphite pulp in Saltkällefjorden mentioned above it was found that the sulphite waste liquor reduced the diversity but also that the most tolerant species were those most tolerant to the low salinity. When the environment in this estuary improved after the sulphite pulp mill was closed down, dead bottoms were first colonised by opportunistic species. Characteristic of these species are their low specialisation and broad tolerance to e.g. salinity. These opportunists form a part of low diversity benthic communities. When pollution increases, these same species are the last to disappear. This suggests that estuarine ecosystems are comparatively more tolerant to certain types of pollution than the systems outside of the estuary. The same was found in North American investigations of polluted estuaries: the "typical" benthic fauna was replaced by the more widely tolerant species characteristic of areas with low salinity and low diversity.
Species of an ecosystem under stress often have high abundance, high rate of reproduction and high genetic variability. This suggests that high genetic diversity is associated with low species diversity.

This line of argument leads to the conclusion that high degrees of individual specialisation and low genetic diversity create great problems of adaptation, causing low stress tolerance. Following this conclusion, an ecosystem such as the coral reef or the tropical rainforest is more sensitive to pollution and other types of stress than e.g. an ecosystem in the brackish water zone.

There are a number of examples besides those given here which indicate that species already living under stress, and low diversity ecosystems, resist additional stress such as pollution better than species and ecosystems that normally form stable, high diversity systems. This is not to infer that the Baltic ecosystem would be more tolerant to e.g. high concentrations of DDT and PCB than other systems, nor that the animals would survive the oxygen depletion that periodically occurs in some of the deep basins in the Baltic. I am convinced, however, that the theoretical arguments offered to declare the Baltic or other brackish water areas to be particularly susceptible are not sufficiently supported to form the basis for either research or administrative decisions. The ecosystems on the Swedish west coast are probably of a more sensitive nature.

I see the problem of ecosystem diversity and stress tolerance as one of the highest research priorities in the field of ecology.

\section{REFERENCES}

${ }^{1}$ B. I. Dybern, Synpunkter på Östersjöns föroreningssituation. IVL-Publ. A 40, 86-108 (1970).

${ }^{2}$ L. H. Forssblad, Redovisning av resultatet från SSVL:s miljövårdsprojekt. IVL-Publ. A 109, 5-10 (1974). 
${ }^{3} \mathrm{~S}$. H. Fonselius, Hydrography of the Baltic deep basins III. Fishery Board of Sweden, ser. Hydrography, No. 23, 1-97(1969).

${ }^{4}$ R. Rosenberg, K. Nilsson and L. Landner, Effects of a sulphate pulp mill on the benthic macrofauna in a firth of the Bothnian Sea. Merentutkimuslait. Julk./Havforskningsinst. Skr. No. 239, 289-300 (1974).

${ }^{5} R$. Rosenberg, Recovery of the littoral fauna in Saltkällefjord subsequent to discontinued operations of a sulphite pulp mill. Thalassia jugosl. 7, 341-351 (1971).
${ }^{6} \mathrm{R}$. Rosenberg, Benthic faunal recovery in a Swedish fjord following the closure of a sulphite pulp mill. Oikos 23, 92-108 (1972).

${ }^{7} R$. Rosenberg, Succession in benthic macrofauna in a Swedish fjord subsequent to the closure of a sulphite pulp mill. Oikos 24, 244-258 (1973).

${ }^{8} \mathrm{R}$. Rosenberg, Spatial dispersion of an estuarine benthic faunal community. J. exp. mar. Biol. Ecol. 15, 69-80 (1974). 